\title{
The incidence detection of tuberculosis in patients with infertility and abnormal uterine bleed: a study in North Indian population
}

\author{
Simmanjit Kaur ${ }^{1}$, Unmesh Santpur ${ }^{1}$, Sunita Mor ${ }^{2 *}$
}

${ }^{1}$ Department of Obstetrics and Gynecology, MMIMSR, Mullana, Ambala, Haryana, India
${ }^{2}$ Department of Obstetrics and Gynecology, MMMCH, Kumarhatti, Solan, Himachal Pradesh, India

Received: 17 June 2019

Accepted: 02 July 2019

*Correspondence:

Dr. Sunita Mor,

E-mail: drsunita.mor@gmail.com

Copyright: (C) the author(s), publisher and licensee Medip Academy. This is an open-access article distributed under the terms of the Creative Commons Attribution Non-Commercial License, which permits unrestricted non-commercial use, distribution, and reproduction in any medium, provided the original work is properly cited.

\begin{abstract}
Background: Tuberculosis (TB) remains a major global health problem, responsible for ill health among millions of people each year. TB ranks as the second leading cause of death from an infectious disease worldwide, after the human immunodeficiency virus (HIV). The latest estimates included in this report are that there were 9.0 million new TB cases in 2013 and 1.5 million TB deaths (1.1 million among HIV-negative people and 0.4 million among HIVpositive people). In India the incidence of genital tuberculosis is nearly about $18 \%$. And in female genital tract it is estimated that $18 \%$ in India suffer from genital TB.

Methods: The study was carried-out during November 2014 to March 2016 at Maharishi Markandeshwar deemed to be University, MMIMSR Mullana (Ambala). A total of 100 females of reproductive age attending the Gynaecology Outpatient were finally recruited on the basis of inclusion and exclusion criteria.

Results: In our study majority i.e. 39 (39.0\%) patient were found in the group of 20-29 years of age followed by 38 $(38.0 \%)$ patients in the group of 30-39 years of age. Only $23(23.0 \%)$ were found in the group of 40-49 years of age. In our study majority i.e. $54(54.0 \%)$ patients were from Haryana followed by $44(44.0 \%)$ patients were from Uttar Pradesh and only $2(2.0 \%)$ patients were from Punjab. Out of 100 patients majority i.e. $76(76.0 \%)$ patients had negative TB with either of investigation and only 24 (24.0\%) patients had positive TB with either of investigation.

Conclusions: Female genital tuberculosis affects the females of reproductive age group. The disease manifests itself as pelvic inflammatory disease in its acute form with menstrual irregularities and later infertility, and is almost always secondary to a primary lesion elsewhere.
\end{abstract}

Keywords: AFB, AUB, Infertility, Menorrhagia, Oligomenorrhoea, Tuberculosis

\section{INTRODUCTION}

Tuberculosis (TB) remains a major global health problem, responsible for ill health among millions of people each year. TB ranks as the second leading cause of death from an infectious disease worldwide, after the human immunodeficiency virus (HIV). The latest estimates included in this report are that there were 9.0 million new TB cases in 2013 and 1.5 million TB deaths
(1.1 million among HIV-negative people and 0.4 million among HIV-positive people). ${ }^{1}$

Though most TB cases and deaths occur among men, the burden of disease among women is also high. In 2013, there were an estimated 3.3 million cases and $510000 \mathrm{~TB}$ deaths among women, as well as an estimated 550000 cases and 80000 deaths among children. ${ }^{1}$ TB mortality is unacceptably high given that most deaths are preventable 
if people can access health care for a diagnosis and the correct treatment is provided. Short-course regimens of first-line drugs that can cure around $90 \%$ of cases have been available for decades. In 1993 World Health Organization (WHO) declared $\mathrm{TB}$ as a global public health emergency, since then major progress has been made. Globally, the TB mortality rate (deaths per 100 000 population per year) has fallen by $45 \%$ since 1990 and TB incidence rates (new cases per $100 \quad 000$ population per year) are decreasing in most parts of the world. Between 2000 and 2013, an estimated 37 million lives were saved through effective diagnosis and treatment. $^{2}$

The WHO monitors the level of TB in every country in the world. In 2014 the estimated worldwide number of new cases of TB was 9.6 million. India, Indonesia and China, were the countries with the highest rates of $\mathrm{TB}$. The rates were $23 \%, 10 \%$ and $10 \%$ of the global total respectively. ${ }^{3}$

In India the incidence of genital tuberculosis is nearly about $18 \% .^{4}$ And in female genital tract it is estimated that $18 \%$ in India suffer from genital TB. ${ }^{5}$ In females the genital organs commonly affected are as follows: fallopian tube (95-100\%), endometrium (50-60\%), ovaries $(20-30 \%)$, cervix $(5-15 \%)$, myometrium $(2.5 \%)$ and vulva/vagina (1\%). ${ }^{6}$ Male genital TB is predominantly associated with tuberculosis of the kidney and prostate, seminal vesicle, epididymis, testes as well as scrotum may occasionally be affected. ${ }^{7}$

There are 22 countries that since 1998 have been considered to be the TB "high burden" countries (HBCs). These are the countries that have been given the highest priority at global level. In addition to India, Indonesia and China, the other countries are Nigeria, Pakistan, South Africa, Bangladesh, Philippines, DR Congo, Ethiopia, Myanmar, UR Tanzania, Mozambique, Viet Nam, Russian Federation, Thailand, Kenya, Brazil, Uganda, Afghanistan, Cambodia \& Zimbabwe. ${ }^{8}$

The 22 HBCs accounted for $83 \%$ of all estimated incident cases worldwide in 2014. The incidence is the number of new cases of active TB disease in a population during a year.

The United States is a country with a low burden of TB. The number of incident TB cases relative to the population size of a country varies greatly among countries. The lowest rates, that is the countries least affected by TB are found mostly in high income countries, including most countries in Western Europe.

India is the country with the highest burden of TB. The WHO statistics for 2015 give an estimated incidence figure of 2.2 million cases of TB for India out of a global incidence of 9.6 million. The TB incidence for India is the number of new cases of active TB disease in India during a certain time period (usually a year). The estimated TB prevalence figure for 2015 is given as 2.5 million. ${ }^{1}$ The TB prevalence is the number of people in India who are living with active TB. Prevalence is usually, but not always given as a percentage of the population.

It is estimated that about $40 \%$ of the Indian population is infected with TB bacteria, the vast majority of whom have latent rather than active TB.

The global prevalence of genital tuberculosis (GTB) is estimated to be 8-10 million cases annually. Reportedly about nine per cent of all extra pulmonary tuberculosis cases are genital TB. It is the root cause in $5-16 \%$ of cases of infertility among Indian women. ${ }^{9,10}$ Genital TB is a chronic disease that often presents with low grade symptomatology and very few specific complaints. Presenting symptoms are generally varied; infertility being the most frequent clinical presentation (43-74\%). Other clinical presentations include oligomenorrhoea (54\%), amenorrhoea (14\%), menorrhagia (19\%), abdominal pain (42.5\%), dyspareunia (5-12\%) and dysmenorrhoea (12-30\%). ${ }^{10}$ The tubercle bacilli reach the genital tract mainly by haematogenous spread from foci outside the genitalia. Haematogenous spread of TB bacilli to the fallopian tubes results in involvement of the sub mucosa (endosalpingitis) at the outer ends with gradual spread medially to the endometrium. Direct spread of infection to the fallopian tubes results in exopsalpingitis with tubercle on the surface. The fallopian tube is the initial site of involvement, affected in almost all cases, followed by endometrium in 50-90 per cent of cases. ${ }^{11}$

The present study was undertaken to detect the incidence of tuberculosis in cases of infertility and in patients with abnormal uterine bleed (AUB) i.e. oligomenorrhea, amenorrhea and menorrhagia.

\section{METHODS}

The study was carried-out during November 2014 to March 2016 as a collaborative clinico-laboratory and molecular diagnostic study jointly at the Department of Obstetrics and Gynecology, Department of Pathology, Biochemistry and Microbiology at Maharishi Markandeshwar deemed to be University, MMIMSR Mullana (Ambala).

A total of 100 females of reproductive age attending the gynaecology outpatient were finally recruited on the basis of inclusion and exclusion criteria. The ethical committee of Maharishi Markandeshwar deemed to be University, MMIMSR Mullana (Ambala) approved the study. Informed consent was obtained from the patients included in this study.

\section{Inclusion criteria}

- All patients of infertility 
- Patients presenting with AUB like oligomenorrhea, menorrhagia and amenorrhea.

\section{Exclusion criteria}

- Patients with proven diagnosis of other causes of infertility i.e. abnormality in ovulation, male factors, endocrine problems, sexual disorders, endometrioses and peritoneal adhesions due to previous abdominal surgery.

\section{The clinical profile of the study subjects}

Detailed histories of these patients were taken particularly in relation to tuberculosis in the past or in the family members. All these patients were subjected to thorough physical, systemic and pelvic examination and findings were filled in the proforma.

- Age

- Duration of married life

- Use of contraception

- Type of infertility: Primary/secondary

- Menstrual abnormalities: Secondary amenorrhea/ Oligomenorrhea/ menorrhagia

- Abdominal pain, chronic pelvic pain and pelvic inflammatory disease (PID)

- Educational and professional background of both partners

- Monthly income of the family

- Constitutional symptoms like loss of weight, loss of appetite and evening rise of temperature

- Screening for past history of tuberculosis of various sites such as lungs, abdomen and lymph nodes. In women who had a previous of tuberculosis, the method of diagnosis of disease, time since diagnosis and duration of treatment was also noted

- In case of secondary infertility, parity details and previous history of abortion, if any was also noted.

\section{All patients were also subjected to following investigations}

- Complete blood count

- Erythrocyte sedimentation rate (ESR)

- Tuberculin test: Mantoux test (Mx): A positive tuberculin tests is defined with an induration size equal to or more than $10 \mathrm{~mm}$

- Chest X-ray was also done for the presence of old foci of pulmonary tuberculosis

- Imaging with abdominal ultrasound (USG) was done as a routine in all infertile patients and AUB

- $\quad$ HIV testing was done in all patients for both partners

- $\mathrm{HbsAg}, \mathrm{HCV}$ and VDRL was also done.

\section{Statistical analysis}

Statistical analysis was performed using SPSS 16.0 software. Unpaired t-test was used to analyze continuous data. Categorical data was compared using Chi-square test. $\mathrm{P}<0.05$ was taken as statistically significant. Relative risk was calculated for abnormal UA PI, UA RI, UA S/D, MCA PI and cerebral-umbilical PI ratio. Multivariate regression was used to analyze effect of multiple vari. All the data was compiled and entered using Microsoft Excel in Windows 13. Analysis was performed using Statistical Package for social Science SPSS version 15.0 (SPSS Inc., Chicago, IL, USA). Value of $p<0.05$ was considered to be statistically significant.

\section{RESULTS}

On the basis of detailed history, the study subjects (100 females fulfilling inclusion criteria) were categorized with regard to their demographic profile, type of infertility, and duration of married life. Patients were also categorized according to their gynecological symptoms, menstrual disturbance, history of contact or past history of TB and history suggestive of active disease.

Table 1: Distribution of patients as per age group.

\begin{tabular}{|lll|}
\hline Age group & Frequency & Percent \\
\hline 20 to 29 years & 39 & 39.0 \\
\hline 30 to 39 years & 38 & 38.0 \\
\hline 40 to 49 years & 23 & 23.0 \\
\hline Total & $\mathbf{1 0 0}$ & $\mathbf{1 0 0 . 0}$ \\
\hline
\end{tabular}

The patients in the study group were between the age group 20 and 49 years. The mean age of the patients was 32.11 years with a standard deviation of 6.229 years.

Table 2: Distribution of patients as per their geographical area.

\begin{tabular}{|lll|}
\hline Geographic area & Frequency & Percent \\
\hline Haryana & 54 & 54.0 \\
\hline Uttar Pradesh & 44 & 44.0 \\
\hline Punjab & 2 & 2.0 \\
\hline Total & $\mathbf{1 0 0}$ & $\mathbf{1 0 0 . 0}$ \\
\hline
\end{tabular}

Table 3: Distribution of patients as per socioeconomic state.

\begin{tabular}{|ll|l|}
\hline Socioeconomic state & Frequency & Percent \\
\hline Lower & 16 & 16.0 \\
\hline Upper lower class & 30 & 30.0 \\
\hline Lower middle class & 30 & 30.0 \\
\hline Upper middle class & 22 & 22.0 \\
\hline Upper class & 2 & 2.0 \\
\hline Total & $\mathbf{1 0 0}$ & $\mathbf{1 0 0 . 0}$ \\
\hline
\end{tabular}

In our study majority i.e. $39(39.0 \%)$ patient were found in the group of 20-29 years of age followed by 38 (38.0\%) patients in the group of 30-39 years of age. Only $23(23.0 \%)$ were found in the group of 40-49 years of age. On analysis, we found that maximum number of Study subjects (39\%) belonged to the age group 20-29 
years suggesting that female genital tuberculosis affects females in their early reproductive age.

In our study majority i.e. $54(54.0 \%)$ patients were from Haryana followed by $44(44.0 \%)$ patients were from Uttar Pradesh and only $2(2.0 \%)$ patients were from Punjab.

When the educational and professional/economical background of the patients was compared in our study 16 $(16.0 \%)$ patients were from lower class followed by 30
$(30.0 \%)$ patients from upper lower class followed by 30 $(30.0 \%)$ patients from lower middle class followed by 22 $(22.0 \%)$ patients from upper middle class and only 2 $(2.0 \%)$ patients were from the upper class.

Table 4: Distribution of patients as per infertility.

\begin{tabular}{|lll|}
\hline Type of infertility & Frequency & Percent \\
\hline Primary infertility & 34 & 34.0 \\
\hline Secondary infertility & 22 & 22.0 \\
\hline Other complaints & 44 & 44.0 \\
\hline
\end{tabular}

Table 5: Distribution of patients as per amenorrhea, menorrhagia and oligomenorrhea.

\begin{tabular}{|lllll|}
\hline Gynecological complaints & Present & & Absent & \\
\cline { 2 - 5 } & Frequency & Percent & Frequency & Percent \\
\hline Amenorrhea & 11 & 11.0 & 89 & 89.0 \\
\hline Oligomenorrhea & 8 & 8.0 & 92 & 92.0 \\
\hline Menorrhagia & 37 & 37.0 & 63 & 63.0 \\
\hline
\end{tabular}

Out of 100 patients $34(34.0 \%)$ patients were having primary infertility followed by $22(22.0 \%)$ patients who were having secondary infertility whereas majority i.e. 44 $(44.0 \%)$ patients were having other complaints.

In our study amenorrhea was present in 11 patient and absent in 89 patients followed by Oligomenorrhea was present in 8 patients and absent in 92 patients followed by majority i.e. 37 patients had menorrhagia whereas it was absent in 63 patients, 44 patients had normal menstrual cycle.

Table 6: Distribution of patients as per other complaints.

\begin{tabular}{|lll|}
\hline Other complaints & Frequency & Percent \\
\hline Dysmenorrhea & 6 & 6.0 \\
\hline Dyspareunia & 2 & 2.0 \\
\hline Vaginal discharge & 5 & 5.0 \\
\hline Urinary complaints & 4 & 4.0 \\
\hline Pelvic pain & 5 & 5.0 \\
\hline No complaints & 78 & 78.0 \\
\hline Total & $\mathbf{1 0 0}$ & $\mathbf{1 0 0 . 0}$ \\
\hline
\end{tabular}

Table 7: Distribution of patients as per past history of TB.

\begin{tabular}{|lll|}
\hline Past history of TBB & Frequency & Percent \\
\hline Present & 25 & 25.0 \\
\hline Absent & 75 & 75.0 \\
\hline Total & $\mathbf{1 0 0}$ & $\mathbf{1 0 0 . 0}$ \\
\hline
\end{tabular}

Out of 100, majority i.e. $78(78.0 \%)$ patients were not having any complaint followed by $6(6.0 \%)$ patients who had dysmenorrhea followed by $2(2.0 \%)$ patients who had dyspareunia followed by $5(5.0 \%)$ patients who had vaginal discharge followed by $4(4.0 \%)$ patients who had urinary complaints followed by $5(5.0 \%)$ patients who had Pelvic pain.

Out of 100 patients, majority i.e. $75(75.0 \%)$ patients were not having past history of Tuberculosis whereas 25 (25.0\%) patients had past history of Tuberculosis. Out of 24 patients diagnosed FGTB by one or more method, 16 $(66.7 \%)$ were positive with past history of tuberculosis and $8(33.3 \%)$ were positive with no past history of tuberculosis.

- p value: $0.000 \quad(<0.05)$ chi square test. This is statistically significant.

Table 8: Distribution of patients as per diagnosis of TB by either of investigations.

\begin{tabular}{|lll|}
$\begin{array}{lll}\text { Diagnosis TB with either of } \\
\text { investigations }\end{array}$ & Frequency & Percent \\
\hline Positive & 24 & 24.0 \\
\hline Negative & 76 & 76.0 \\
\hline Total & $\mathbf{1 0 0}$ & $\mathbf{1 0 0 . 0}$ \\
\hline
\end{tabular}

Out of 100 patients majority i.e. $76(76.0 \%)$ patients had negative TB with either of investigation and only 24 (24.0\%) patients had positive TB with either of investigation).

\section{DISCUSSION}

Female genital tuberculosis affects the females of reproductive age group. The disease manifests itself as pelvic inflammatory disease in its acute form with menstrual irregularities and later infertility, and is almost always secondary to a primary lesion elsewhere. The disease frequently remains unnoticed even in most of the 
tertiary health care set ups particularly in developing countries. The true incidence of this important but relatively ignored form of extra pulmonary tuberculosis remains unknown as the disease poses unconquered diagnostic challenges mainly because the primary symptoms are usually non-characteristic. ${ }^{12}$ Infertility is a well-known sequela. Early diagnosis invariably helps to speed up the decision-making process and markedly reduces the time lag in starting anti-tubercular therapy. Although, the reported incidence of genital tuberculosis in Asian and Western countries varies between $0.69 \%$ (in Australia) and $18 \%$ (in India); the actual incidence may be higher because a large proportion of cases go unreported due to lack of sensitive and specific investigations..$^{10,11}$

As a result, the disease is either not diagnosed or diagnosed at an advanced stage when the tubal damage has already occurred.

The present study was carried out in the department of obstetrics and gynaecolgy MMIMSR, Mullana, Ambala. The study was conducted on 100 patients with infertility and AUB.

With regard to incidence of genital tuberculosis, it is often difficult to gauge the factual magnitude of the problem as the disease initially presents without symptoms and due to diagnostic difficulties it is picked only during the investigation for infertility.

The incidence also varies greatly according to the socioeconomic and public health conditions; therefore, there is wide variation in figures published from various countries.

In the present study the incidence of GTB is found to be $2 \%$, similarly Srinivas et al, found $2.08 \%$ in their study and Patel $\mathrm{S}$ et al, reported incidence of GTB in females as $1.25 \% .^{12,13}$

Our study shows that genital tuberculosis affects women in relatively young age group as maximum patients belonged to the age group 20 to 35 years of age. This is in agreement with the previous studies. This finding is in conformity with the findings of Chakarborthy AK et al, and Patel $\mathrm{S}$ et al, who reported females with Genital TB in their studies ie. $46.7 \%$ and $47.6 \%$ respectively in the age group of 21-30 years. ${ }^{13,14}$

Rozati R et al, study also demonstrated majority (80\%) their sample in the age group of 21-30 years, Sharma $\mathrm{N}$ et al, found majority of cases in age group of 20-45 years. ${ }^{15,16}$ Usharani $M$ et al, reported majority of cases of GTB were in the age group of $20-25$ years. ${ }^{17}$

Muechler et al, also reported highest incidence of Genital TB in the age group of 21-30 years. ${ }^{18}$
The reason for maximum cases in this group could be because, after puberty the blood supply to the pelvic organs is increased and as a result, more bacilli could reach this site and infect the reproductive organs .19 In such a scenario, even the dormant bacteria can get reactivated and cause infection leading to more number of young patients getting afflicted to genital tuberculosis leading to infertility.

In the present study (34\%) of females were showing primary infertility. Our incidence is comparable to the incidence in the study done by Puri S et al, found $46.6 \%$ cases of GTB were having primary infertility. ${ }^{20}$ Others studies which were comparable to our study was given by Chakarborty AK et al, and Thangappah RBP et al, who reported infertility as main symptom in $52.5 \%$ and $58.3 \%$ of GTB cases respectively. ${ }^{14,21}$

The result of present study was in conformity with the findings of Patel, and Rana T et al, who reported (44\%) and $(70.6 \%)$ of females with GTB were showing primary infertility. ${ }^{13,22}$

Past history of tuberculosis was present in approximately $25 \%$ of patients in the form of pulmonary, lymph node, abdominal, spine, skin, cervical lymphadenopathy and bone tuberculosis. Some these patients received antitubercular therapy (ATT) for 9 months to 1.5 years. Among the patients positive for genital tuberculosis, past history of tuberculosis was present in 18 (51.4\%) patients. Previous studies have also shown the association of past history tuberculosis with present disease.

Study conducted by Rana $\mathrm{T}$ et al, found $29.3 \%$ of cases with prior history of TB. ${ }^{22}$ Similar findings were reported by Patel $\mathrm{S}$ et al, and Shukla et al, who found prior history of $\mathrm{TB}$ in $19.05 \%$ and $20 \%$ cases respectively. ${ }^{13,23}$ Thangappah RBP et al, reported previous history of TB in $5.5 \%$ cases. $^{21}$

\section{Symptoms versus genital tuberculosis}

In the present study the majority of the females were having infertility $56 \%$ followed by menorrhagia $37 \%$ as the main symptom. The frequency of amenorrhoea, oligomenorrhoea, dysmenorrhea, dyspareunia, pelvic pain, vaginal discharge, urinary complaints were $11 \%$, $8 \%, 6 \%, 2 \%, 5 \%, 5 \%, 4 \%$ respectively.

Similar results were seen by Chakarborty AK et al, who reported infertility as the most common symptom $52.5 \%$, menstrual disturbances were observe din $27.5 \%$ with amenorrhoea $(50 \%)$ being most common followed by oligomenorrhoea (21\%) and menorrhagia (21\%). $12.9 \%$ females had leucorrhea. ${ }^{14}$ The frequencies of vulval ulcer, lower abdominal mass and uterus prolapse were $1.72 \%$, $3,5 \%, 1.72 \%$ respectively. Patel $\mathrm{S}$ et al, also demonstrated $44 \%$ infertility in females with GTB. ${ }^{13}$ The incidence of vaginal bleeding, uterine bleeding, Postmenopausal bleeding, lower abdominal mass and 
vaginal discharge as $18 \%, 14.28 \%, 2 \%, 4.76 \%$ and $4 \%$ respectively.

\section{CONCLUSION}

Genital tuberculosis is a major socioeconomic burden in india, afflicting millions of people, mostly in reproductive age group.

Funding: No funding sources

Conflict of interest: None declared

Ethical approval: The study was approved by the Institutional Ethics Committee

\section{REFERENCES}

1. World Health Organization. Global tuberculosis control report, 2015. Available at: http://www.who.int/tb/publications/global_report/20 15/en/index.html. Accessed on September 2016.

2. The Global Plan to Stop TB, 2011-2015. Geneva, World Health Organization, 2010 (WHO/HTM/STB/2010.2). Available at: http://w w w.stoptb.org/assets/documents/global/plan/TB_ GlobalPlanToStopTB2011-2015.pdf. Accessed on September 2016.

3. World Health Organization. Global tuberculosis control report. 2015. Available at: www.who.int/tb/publications/global_report/gtbr2015 _executive_summary.pdf. Accessed on September 2016.

4. Marjorie PG, Holenarasipur RV. Extrapulmonary tuberculosis: an overview. Am Fam Physician. 2005;72:1761-8.

5. Vithalani N, Udani PM, Vithalani N. A study of 292 autopsies proved cases of tuberculosis. Indian $\mathrm{J}$ Tuber. 1982;29:93-7.

6. Gatoni DK, Gitau G, Kay V, Ngwenya S, Lafong C, Hasan A. Female genital tuberculosis. Obstet Gynecol. 2005;7:75-9.

7. Ali A, Abdallah T. Clinical presentation and epidemiology of female genital tuberculosis in eastern Sudan. Int J Gynaecol Obstet. 2012;8:236-8.

8. Use of high burden country lists for TB by WHO in the post-2015 era High-burden-country-lists. Available at: http://www.tbfacts.org/countriestb/\#sthash.8kCWePhQ.2qUCH0YL.dpuf. Accessed on September 2016.

9. Malhotra B, Sinha S, Hooja S, Vyas L. Rapid diagnosis of genital tuberculosis by Real Time PCR. J South Asian Federation Obstet Gynae. 2012;4(1):39-42.

10. Bose M. Female genital tract tuberculosis: How long will it elude diagnosis? Indian J Med Res. 2011;134:13-4.
11. Singh MM, Bhargava AM, Jain KP. Tuberculous peritonitis: an evaluation of pathogenetic mechanisms, diagnostic procedures and therapeutic measures. N Engl J Med. 1968;281:1091-4.

12. Srinivas Rao MS, Pavani K, Uma M, Krishna K, Vinayaraj EV, Dass M. To evaluate the prevalence of female genital tuberculosis in Hyderabad. Int J Res Med Sci. 2013;1(4):421-3.

13. Patel S, Dhand PL. Hospital based study on female genital tuberculosis in Central India. Int $\mathbf{J}$ Med Res Review. 2016;4(2):20-6.

14. Chakraborty S, Chakraborty AK, Patra SP, Bhattacharya SK. Demonstration of acid-fast bacilli in tissues and evaluation of atypical tuberculous lesions. J Indian Med Assoc. 1993;91(2):30-3.

15. Rozati R, Roopa S. Evaluation of women with infertility and genital tuberculosis . J Obstet Gynecol India. 2006;56(5):423-6.

16. Sharma N, Sharma V, Singh PR, Sailwal S, Kushwaha RS, Diagnostic value of PCR in genitourinary tuberculosi. Indian $\mathrm{J}$ Clin Biochem. 2013;28(3):305-8.

17. Usharani B, Muthuraj M, Radhakrishnan B, James JB, Govindarajan S, Raman KV. Molecular epidemiology of female genital tuberculosis leading to infertility. Int J Current Microbiol Applied Sci. 2016;5(8):731-40.

18. Muechler E, Minkowitz S. Postmenopausal endometrial tuberculosis. Obstet Gynecol. 1971;38(5):768-70.

19. Crofton J, Horne N, Miller F. Clinical tuberculosis. 1st edn. London: Macmillan Education Ltd. 1992;502-10.

20. Puri S, Bansal B. Diagnostic value of PCR in female genital TB and its therapeutic implications. J Obstet Gynecol India. 2009;59(1):67-70.

21. Thangappah RBP, Paramasivan CN, Narayanan S. Evaluating PCR, culture and histopathology in the diagnosis of female genital tuberculosis. Indian $\mathbf{J}$ Med Res. 2011;134:40-6.

22. Rana T, Singh UB, Kulshrestha V, Kaushik A, Porwal C, Agarwal N. Utility of reverse transcriptase PCR and DNA-PCR in the diagnosis of female genital tuberculosis. J Med Microbiol. 2011;60(4):486-91.

23. Shukla S, Acharya N, Acharya S, Rajput DP, Vagha S. Fictitious pseudo Meig's syndrome: a medical emergency. J College Med Sci-Nepal. 2011;7:57-64.

Cite this article as: Kaur S, Santpur U, Mor S. The incidence detection of tuberculosis in patients with infertility and abnormal uterine bleed: a study in North Indian population. Int J Reprod Contracept Obstet Gynecol 2019;8:3041-6. 